\title{
2-oxo-PCE: ketamine analogue on the streets
}

\section{Hong Kong Med J 2017;23:665-6}

DOI: 10.12809/hkmj177089

To the Editor-New psychoactive substances are recently emerged drugs that are chemically or pharmacologically similar to conventional drugs of abuse. Our laboratory has repeatedly identified new psychoactive substances in Hong Kong. ${ }^{1-3}$

We report the identification of 2-oxoPCE [2-phenyl-2-(ethylamino)-cyclohexanone, also known as deschloro-N-ethyl-ketamine or deschloro-N-ethyl-norketamine] in urine samples of multiple unrelated patients in October 2017 with suspected ketamine abuse or related poisoning features. An unidentified substance was detected in these samples by general toxicology screening using high-performance liquid chromatographydiode array detection; further investigations at our laboratory confirmed the unidentified substance as 2-oxo-PCE by liquid chromatography-tandem mass spectrometry. This compound is not routinely covered by general toxicology screening and in our experience does not cross-react with at least one bedside ketamine immunoassay (ABON; Abon Biopharm [Hangzhou] Co Ltd, Hangzhou, PRC).

The drug, 2-oxo-PCE, is a new psychoactive substance in the arylcyclohexylamine class, with structural similarity to ketamine and methoxetamine. Historically, it was synthesised in 1962 in an attempt to develop a short-acting phencyclidine derivative, a project that culminated in the discovery of ketamine. ${ }^{4}$ Drugs of this class are known to possess $\mathrm{N}$-methyl-D-aspartate receptor antagonist activity with variable effects towards other receptors, ${ }^{4}$ resulting in dissociative effects clinically. The use of this drug has been recently reported in Germany. ${ }^{5}$ To date, there have been no clinical poisoning reports of this drug in the scientific literature, but user reports on the internet show that 2-oxo-PCE causes a similar effect to ketamine, but is more potent.

Ketamine is one of the most prevalent drugs of abuse in Hong Kong. Our findings of 2-oxo-PCE in a cluster of unrelated patients with suspected ketamine abuse give rise to the suspicion of substitution of 2oxo-PCE for ketamine in street supplies, possibly to evade detection. In patients presenting with ketamine-like toxidrome but with a negative urine toxicology result, the use of 2-oxo-PCE may need to be considered. Analysis of 2-oxo-PCE in urine specimens is provided in our laboratory and can be 
requested by clinicians in Hong Kong.

\section{Declaration}

All authors have disclosed no conflicts of interest.

1,2 YK Chong, FHKCPath, FHKAM (Pathology)

${ }^{1}$ Magdalene HY Tang, PhD

${ }^{2}$ CL Chan, MSc

${ }^{3}$ YK Li, FHKCEM, FHKAM (Emergency Medicine)

1,2 CK Ching, FRCPA, FHKAM (Pathology)

1,2 Tony WL Mak *, FHKCPath, FHKAM (Pathology)

${ }^{1}$ Hospital Authority Toxicology Reference Laboratory

2 Chemical Pathology Laboratory, Department of Pathology

${ }^{3}$ Accident and Emergency Department

Princess Margaret Hospital, Laichikok, Hong Kong

*Corresponding author: makwl@ha.org.hk

\section{References}

1. Lau NK, Chong YK, Tang MH, Ching CK, Mak TW. Desoxy-D2PM: a novel psychoactive substance in convenience stores. Hong Kong Med J 2016;22:515.

2. Tang M, Ching CK, Tse ML, et al. Surveillance of emerging drugs of abuse in Hong Kong: validation of an analytical tool. Hong Kong Med J 2015;21:114-23.

3. Poon WT, Lai CF, Lui MC, Chan AY, Mak TW. Piperazines: a new class of drug of abuse has landed in Hong Kong. Hong Kong Med J 2010;16:76-7.

4. Morris H, Wallach J. From PCP to MXE: a comprehensive review of the non-medical use of dissociative drugs. Drug Test Anal 2014;6:614-32.

5. Piontek D, Hannemann TV. Medikamentenmissbrauch und der Konsum von neuen psychoaktiven Substanzen (NPS) in unterschiedlichen Risikopopulationen. Ergebnisse des Projekts Phar-Mon NPS aus den Jahren 2015 und 2016 [in German]. München: IFT Institut für Therapieforschung; 2017. 